\title{
Clinicopathological analysis for recurrence of stage Ib gastric cancer (according to the second English edition of the Japanese classification of gastric carcinoma)
}

\author{
Takashi Yokoyama $\cdot$ Kiyoshi Kamada $\cdot$ Yoshikazu Tsurui $\cdot$ \\ Hisanori Kashizuka $\cdot$ Eiji Okano $\cdot$ Sanehito Ogawa • \\ Shinsaku Obara $\cdot$ Mitsutoshi Tatsumi
}

Received: 27 December 2010/Accepted: 30 March 2011/Published online: 18 May 2011

(c) The International Gastric Cancer Association and The Japanese Gastric Cancer Association 2011

\begin{abstract}
Background The prognosis for patients with stage Ib (second English edition of the Japanese classification of gastric carcinoma) gastric cancer is promising, with an expected 5-year survival of $90 \%$. Despite this relatively high survival rate, the outcome for patients who experience recurrence is poor. To date, however, prognostic and recurrence factors for stage $\mathrm{Ib}$ gastric cancer are poorly understood, and appropriate adjuvant chemotherapy protocols have not been developed.

Methods We retrospectively analyzed data from 86 stage Ib gastric cancer patients who underwent curative gastrectomy to determine the rates and predictive factors of recurrence.

Results Eleven patients showed recurrence, with a $12.8 \%$ 5-year cumulative recurrence rate. Nearly all of these patients were initially histologically diagnosed with poorly differentiated adenocarcinoma. Based on univariate analyses, recurrence was associated with gender and histological type. Multivariate analyses revealed that the only independent risk factor for recurrence was histologically undifferentiated-type adenocarcinoma. The 5-year survival rate of patients with undifferentiated-type adenocarcinoma was $84 \%$. The predominant recurrence pattern was peritoneal dissemination, and was typically observed $1-3$ years post-resection.
\end{abstract}

T. Yokoyama - K. Kamada - Y. Tsurui · H. Kashizuka ·

E. Okano $\cdot$ S. Ogawa $\cdot$ S. Obara $\cdot$ M. Tatsumi

Department of Surgery, Hoshigaoka Kouseinenkin Hospital,

4-8-1 Hoshigaoka, Hirakata, Osaka 573-8511, Japan

T. Yokoyama $(\varangle)$

Department of Surgery, Takanohara Central Hospital,

1-3-3 Ukyo, Nara 631-0805, Japan

e-mail: yokoyamatakashi1@yahoo.co.jp
Conclusion This retrospective study identified undifferentiated-type adenocarcinoma as the only risk factor for recurrence in stage $\mathrm{Ib}$ gastric cancer patients. Although randomized controlled studies are necessary, stage $\mathrm{Ib}$ gastric cancer patients with this identified recurrence risk factor would be candidates for adjuvant chemotherapy.

Keywords Gastric carcinoma - Stage I - Adjuvant chemotherapy $\cdot$ Recurrence $\cdot$ Prognostic factor

\section{Introduction}

The mortality of gastric cancer has decreased significantly in Japan, because various approaches and therapies, including gastric cancer screening, surgery, and chemotherapy, have been developed. A more radical standardized surgical approach to treatment involving systematic lymph node dissection is considered to have contributed to better survival outcomes [1]. In addition, the use of the oral fluoropyrimidine derivative $\mathrm{S}-1$ as adjuvant chemotherapy after curative surgery in patients with stage II or III gastric cancer in accordance to second English edition of the Japanese classification of gastric carcinoma (second English edition) [2] has proven to be effective [3]. Despite these approaches for reducing mortality, further improvement in the prognosis of this disease requires the identification of those patients with early gastric cancer who are at risk for recurrence.

Stage I gastric cancer (second English edition) was divided into stages Ia and Ib, with the latter having a relatively poor prognosis compared to the former. Although a number of risk factors have been identified for all stages of gastric cancer [4-6], because of the relatively low incidence of recurrence after curative resection for stage $\mathrm{Ib}$ 
gastric cancer, the risk factors and rates of recurrence for this stage are unclear.

Here, we conducted a retrospective study to determine the rates, patterns, and prognostic factors of recurrence of stage Ib gastric cancer, and to consider the potential treatment options for further improving the prognosis of gastric cancer patients at risk for recurrence.

\section{Patients and methods}

Patients

We retrospectively reviewed data from 593 patients with primary gastric cancer who underwent gastrectomy in our hospital between January 2000 and December 2008 . Among these patients, 99 (17\%) were identified by histology as having stage Ib gastric cancer (T1N1 or T2N0), based on the second English edition [2]. About lymph node metastasis, the regional lymph nodes are classified into three groups depending upon the location of the primary tumor, and ' $\mathrm{N} 1$ ' indicates metastasis to Group 1 lymph nodes, but no metastasis to Group 2 or Group 3 lymph nodes [2]. Histopathologically, papillary and tubular adenocarcinomas were grouped together as differentiated-type adenocarcinoma, while poorly differentiated and mucinous adenocarcinomas and signet-ring cell carcinoma were regarded as undifferentiated-type adenocarcinoma. After gastrectomy, the patients underwent follow-up examinations every 6 months for 5 years and thereafter at intervals of 12 months. The median follow-up period was 6.0 years. The recurrence of gastric cancer was confirmed by physical findings, radiological and endoscopic examinations, and reoperation. The clinical records of patients and telephone interviews were used for catamnestic follow-up. Four patients $(4.0 \%)$ were lost to follow-up because of no room visit and telephone disconnection and 9 died from other diseases (cardiac disease 2, pneumonia 2, lung cancer 1, pancreas cancer 1 , cerebral apoplexy 1 , and unknown 2 ), leaving 86 patients included in the analysis. The clinicopathological characteristics of the 86 patients are shown in Table 1. Mean and median ages were $63.2 \pm 9.7$ and 63 (range 40-87) years, respectively, and approximately twice as many male (58) as female patients (28) were included. With regard to surgery, all patients underwent a total or distal gastrectomy with lymph node dissection to the $\mathrm{D} 1+\alpha, \beta$, or $\mathrm{D} 2$ level in accordance with the second English edition of the Japanese classification of gastric carcinoma [2]. Histologically, 55 of the 86 patients were diagnosed with undifferentiated-type gastric cancer, 23 of whom were female ( $82 \%$ of females) and 32 were male (55\%). Fifteen patients had lymph node metastasis, and 14 patients received adjuvant chemotherapy.
Table 1 Clinicopathological characteristics of stage Ib gastric cancer patients $(n=86)$

\begin{tabular}{|c|c|}
\hline \multicolumn{2}{|l|}{ Age (years) } \\
\hline Mean \pm SD & $63.2 \pm 9.7$ \\
\hline Median (range) & $63(40-87)$ \\
\hline \multicolumn{2}{|l|}{ Gender } \\
\hline Male & 58 \\
\hline Female & 28 \\
\hline \multicolumn{2}{|l|}{ Location } \\
\hline Upper & 20 \\
\hline Middle & 43 \\
\hline Lower & 23 \\
\hline \multicolumn{2}{|l|}{ Gross appearance } \\
\hline 0 & 35 \\
\hline 1 & 2 \\
\hline 2 & 28 \\
\hline 3 & 18 \\
\hline 4 & 3 \\
\hline \multicolumn{2}{|l|}{ Tumor size (mm) } \\
\hline Mean \pm SD & $38.8 \pm 22.0$ \\
\hline Median (range) & $30(10-130)$ \\
\hline \multicolumn{2}{|l|}{ Lymph node dissection } \\
\hline D1 & 38 \\
\hline D2 & 48 \\
\hline Operation time (min) & $220.0 \pm 59.0$ \\
\hline Blood loss (ml) & $392.8 \pm 245.8$ \\
\hline \multicolumn{2}{|l|}{ Histology } \\
\hline Differentiated & $31(\mathrm{M}: \mathrm{F}=26: 5)$ \\
\hline Undifferentiated & $55(\mathrm{M}: \mathrm{F}=32: 23)$ \\
\hline \multicolumn{2}{|l|}{ Depth of tumor invasion } \\
\hline $\mathrm{m}$ & 2 \\
\hline $\mathrm{sm}$ & 13 \\
\hline $\mathrm{mp}$ & 39 \\
\hline ss & 32 \\
\hline \multicolumn{2}{|l|}{ Lymph node metastasis (n) } \\
\hline 0 & 71 \\
\hline 1 & 15 \\
\hline \multicolumn{2}{|l|}{ Lymphatic invasion (ly) } \\
\hline 0 & 3 \\
\hline 1 & 81 \\
\hline 2 & 2 \\
\hline \multicolumn{2}{|l|}{ Vascular invasion (v) } \\
\hline 0 & 82 \\
\hline 1 & 4 \\
\hline \multicolumn{2}{|l|}{ Curability } \\
\hline A & 81 \\
\hline B & 5 \\
\hline $\mathrm{C}$ & 0 \\
\hline \multicolumn{2}{|l|}{ Adjuvant chemotherapy } \\
\hline+ & 14 \\
\hline- & 72 \\
\hline Patients with recurrence & $11(12.8 \%)$ \\
\hline Five-year survival rate & $90 \%$ \\
\hline
\end{tabular}

$m$ mucosal, $s m$ submucosal, $m p$ muscularis propria, $s s$ subserosal 
Statistical analysis

Univariate analyses to compare variables in patients with and without recurrence were performed using the $\chi^{2}$ and Mann-Whitney $U$-tests. Multivariate analyses of factors associated with recurrence were conducted using a logistic regression model. Survival was calculated by the KaplanMeier method. A $p$ value of $<0.05$ was considered to indicate statistical significance.

\section{Results}

Clinicopathological analysis of patients with recurrence

The results of the univariate analyses for factors associated with recurrence in stage Ib gastric cancer are summarized in Table 2. The recurrence rate was higher for patients who were female and for those who had histologically undifferentiated-type adenocarcinoma. Age, tumor location, gross appearance, tumor size, depth of tumor invasion, lymph node metastasis, lymphatic and vascular invasion, curability, and adjuvant chemotherapy did not influence recurrence. Additionally, there was no significant difference in recurrence in relation to surgical stress (operation time, blood loss) and curability.

\section{Risk factors for recurrence}

To determine the independent risk factors involved in the recurrence of stage Ib gastric cancer, significant factors identified by univariate analysis (gender, histological type) and the variables found to be of importance in previous studies (lymph node metastasis, lymphatic and vascular invasion, gross appearance) [4-10] were subjected to logistic regression analysis (Table 3 ). It was revealed that the only independent risk factor for recurrence was histologically undifferentiated-type adenocarcinoma ( $p=0.0069)$.

\section{Survival curves}

The cumulative recurrence rate of the stage $\mathrm{Ib}$ gastric cancer patients was $12.8 \%$ (11 of 86 patients) and 10 of the 11 patients with recurrence died; the 5-year survival rate was $90 \%$ calculated by the Kaplan-Meier method. The overall 5-year survival rate $(84 \%)$ of patients with undifferentiated-type adenocarcinoma was lower than that of the patients with differentiated-type (100\%) (Fig. 1).

Clinicopathological features of patients with recurrence

Of the 11 patients with recurrence, nearly all were initially histologically diagnosed with poorly differentiated
Table 2 Univariate analysis of factors associated with recurrence in stage Ib gastric cancer

\begin{tabular}{|c|c|c|c|}
\hline & $\begin{array}{l}\text { Without } \\
\text { recurrence } \\
(n=75)\end{array}$ & $\begin{array}{l}\text { With } \\
\text { recurrence } \\
(n=11)\end{array}$ & $p$ value* \\
\hline \multicolumn{4}{|l|}{ Age (years) } \\
\hline$\leq 63$ & 39 & 7 & \multirow[t]{2}{*}{0.476} \\
\hline$>63$ & 36 & 4 & \\
\hline \multicolumn{4}{|l|}{ Gender } \\
\hline Male & 54 & 4 & \multirow[t]{2}{*}{0.019} \\
\hline Female & 21 & 7 & \\
\hline \multicolumn{4}{|l|}{ Location } \\
\hline Upper & 18 & 2 & \multirow[t]{3}{*}{0.908} \\
\hline Middle & 37 & 6 & \\
\hline Lower & 20 & 3 & \\
\hline \multicolumn{4}{|l|}{ Gross appearance } \\
\hline 0 & 31 & 4 & \multirow[t]{5}{*}{0.766} \\
\hline 1 & 2 & 0 & \\
\hline 2 & 25 & 3 & \\
\hline 3 & 15 & 3 & \\
\hline 4 & 2 & 1 & \\
\hline \multicolumn{4}{|l|}{ Tumor size (mm) } \\
\hline$\leq 30$ & 38 & 7 & \multirow[t]{2}{*}{0.427} \\
\hline$>30$ & 37 & 4 & \\
\hline \multicolumn{4}{|l|}{ Histology } \\
\hline Differentiated & 31 & 0 & \multirow[t]{2}{*}{0.006} \\
\hline Undifferentiated & 44 & 11 & \\
\hline \multicolumn{4}{|c|}{ Depth of tumor invasion } \\
\hline $\mathrm{m}, \mathrm{sm}$ & 13 & 2 & \multirow[t]{2}{*}{0.945} \\
\hline $\mathrm{mp}, \mathrm{ss}$ & 62 & 9 & \\
\hline \multicolumn{4}{|c|}{ Lymph node metastasis (n) } \\
\hline 0 & 62 & 9 & \multirow[t]{2}{*}{0.945} \\
\hline 1 & 13 & 2 & \\
\hline \multicolumn{4}{|c|}{ Lymphatic invasion (ly) } \\
\hline 0 & 3 & 0 & \multirow[t]{3}{*}{0.779} \\
\hline 1 & 71 & 11 & \\
\hline 2 & 2 & 0 & \\
\hline \multicolumn{4}{|c|}{ Vascular invasion (v) } \\
\hline 0 & 71 & 11 & \multirow[t]{2}{*}{0.986} \\
\hline 1 & 4 & 0 & \\
\hline \multicolumn{4}{|c|}{ Adjuvant chemotherapy } \\
\hline+ & 13 & 1 & \multirow[t]{2}{*}{0.683} \\
\hline- & 62 & 10 & \\
\hline
\end{tabular}

$* p$ values in italics are significant

adenocarcinoma, and lymph node metastasis was positive in 2 at the time of the primary operation (Table 4). All 11 patients underwent potentially curative gastrectomy for gastric cancer, and seven patients experienced recurrence within 2 years of the surgery. The median time interval between the primary operation and recurrence was 652 
(range 158-2616) days. Seven patients had peritoneal dissemination, and one each had liver, mixed type, local, and lymph node recurrence. Deaths were most frequent within 2 years of recurrence, with only one patient living past the follow-up period ( $>1865$ days).

Table 3 Multivariate analysis of factors associated with recurrence

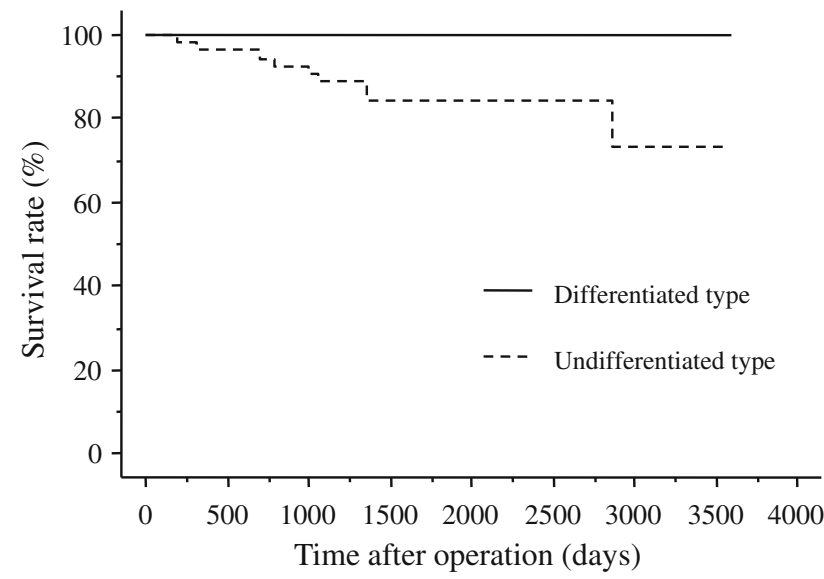

Fig. 1 Overall survival for stage Ib gastric cancer patients according to initial histological type of cancer

\section{Discussion}

Although the prognosis of stage Ib gastric cancer is excellent and adjuvant chemotherapy is not generally recommended, postoperative recurrence does occur in a small percentage of patients. In our retrospective study, the cumulative recurrence rate among 86 patients with stage $\mathrm{Ib}$ gastric cancer treated by curative gastrectomy was $12.8 \%$, and the rate was higher for patients who had histologically undifferentiated-type adenocarcinoma. The predominant recurrence pattern in these patients was peritoneal dissemination, which typically occurred 1-3 years after the initial gastrectomy. In patients with risk factors for recurrence, postoperative treatment may be a reasonable option to improve the prognosis of gastric cancer.

In gastric cancer, the two most common recurrence patterns are hematogenous recurrence, in relatively earlystage cancer $[7,8,11,12]$ and peritoneal dissemination in advanced gastric cancer [4, 13]. In the present study, peritoneal dissemination was observed in seven of the patients with recurrence $(64 \%)$, with one each having hematogenous and mixed-type recurrence. Because all patients with recurrence had been originally diagnosed with undifferentiated adenocarcinoma, peritoneal dissemination recurrence was the major form, regardless of the initial tumor depth and lymph node metastasis [4]. Additionally, for pathological evaluation of the tumor depth of invasion, one or two areas of deepest invasion were sectioned and only hematoxylin-eosin staining was done, according to the second English edition [2]. There is a possibility that some of the tumors in the seven patients with recurrence who had a depth of subserosal (ss) may have had minute invasion of the serosa that could only be detected by examining multiple sections or scrutinizing by immunohistochemistry.

Table 4 Clinicopathological characteristics of patients with recurrence

\begin{tabular}{llllllllll}
\hline $\begin{array}{l}\text { Age } \\
\text { (years) }\end{array}$ & Gender & $\begin{array}{l}\text { Size } \\
(\mathrm{mm})\end{array}$ & Gross & Histology & Depth & $\begin{array}{l}\text { Nodal } \\
\text { status }\end{array}$ & $\begin{array}{l}\text { Time interval between } \\
\text { operation and } \\
\text { recurrence (days) }\end{array}$ & $\begin{array}{l}\text { Recurrence } \\
\text { mode }\end{array}$ & $\begin{array}{l}\text { Time interval between } \\
\text { recurrence and } \\
\text { death (days) }\end{array}$ \\
\hline 42 & F & 35 & 3 & por2 & ss & n0 & 652 & Local & 137 \\
50 & M & 40 & 2 & por2 & ss & n0 & 607 & Peritoneal & 96 \\
50 & F & 15 & 0 -IIc & por2 & ss & n0 & 896 & Peritoneal & 463 \\
51 & M & 25 & 3 & por1 & ss & n0 & 713 & Lymph node & 340 \\
52 & F & 15 & 0 -IIc & por2 & mp & n0 & 2616 & Peritoneal & 253 \\
52 & F & 45 & 2 & muc & mp & n0 & 409 & Liver, Peritoneal & $>1865$ (living) \\
58 & F & 100 & 4 & por2 & ss & n0 & 804 & Peritoneal & 556 \\
66 & M & 30 & 3 & por2 + sig & ss & n0 & 234 & Peritoneal & 77 \\
67 & F & 20 & 2 & por2 + sig & sm1 & n1 & 158 & Peritoneal & 369 \\
74 & F & 30 & 0 -IIc + IIa & por2 + sig & ss & n0 & 604 & Liver & 440 \\
81 & M & 25 & $0-$-IIc & por2 & sm2 & n1 & 2431 & 399 \\
\hline
\end{tabular}

por poorly differentiated adenocarcinoma, sig signet ring cell carcinoma, muc mucinous carcinoma 
Such minute invasion of the serosa which could not be detected by routine staging procedures might have led to the peritoneal recurrence.

With regard to the correlation between risk factors for recurrence and clinicopathological factors, a number of risk factors have been identified for all stages of gastric cancer; these include lymph node metastasis and performance status [4-6]. Furthermore, a few researchers have examined the risk factors of early gastric cancer in more detail. For example, Ichiyoshi et al. reported that elevated-type carcinoma, positive lymph node metastasis, and invasion of lymphatic and venous vessels were significantly associated with a high risk of recurrence [9]. Researchers have proposed that lymph node metastasis is one of the most important risk factors of early gastric cancer, and that the $\mathrm{N}$ stage correlates with the 5-year survival rate $[7,8,10]$. In the present study, lymph node metastasis was not an independent risk factor for recurrence. This could indicate that tumor invasion to T2 (muscularis propria [mp], ss) similarly to lymph node metastasis, influenced the prognosis in patients with stage Ib gastric cancer. Furthermore, in our patients, lymphatic and vascular metastasis was controlled solely by surgery because of the relatively low-grade lymphatic and vascular invasion. It has been reported that lymph node dissection might open lymphatic channels and spread viable cancer cells into the peritoneal cavity [14, 15], and it has also been reported that peritoneal recurrence was closely related to undifferentiated-type adenocarcinoma [4]. In fact, our T1N1 patient with peritoneal recurrence had five lymph node metastases, and 12 of the other T1N1 patients each had one lymph node metastasis. In accordance with these features, in the present study, the only risk factor for recurrence in stage $\mathrm{Ib}$ gastric cancer was histologically undifferentiated-type adenocarcinoma.

Although the 5-year survival rate among our 99 stage $\mathrm{Ib}$ gastric cancer patients was $90 \%$, a result consistent with a previously reported value [2], the rate in patients with histologically undifferentiated-type adenocarcinoma was $84 \%$. These rates are nearly equivalent to the reported rates in stage II gastric cancer patients in the Adjuvant Chemotherapy Trial of TS- 1 for Gastric Cancer (ACTS-GC) [3]. Since the risk factors in stage Ib gastric cancer patients are different from those in patients with all other stages of gastric cancer, the patients who require further treatment are different between these two groups.

In gastric cancer treatment, complete resection of the primary tumor, including an adequate resection margin and lymphadenectomy to reduce the incidence of locoregional failure, is considered standard treatment. However, based on the high rate of peritoneal recurrence observed in our study, surgery alone is considered to be an inadequate treatment approach for resolving gastric cancer, and other approaches for reducing peritoneal recurrence are needed.
In the subgroup analysis of the ACTS-GC, the efficacy of S-1 in undifferentiated-type adenocarcinoma was slightly better than that in differentiated-type adenocarcinoma [3]. Furthermore, in a late phase II trial, the response rates according to tissue types were 28.0 and $52.0 \%$ for the intestinal and diffuse types of adenocarcinoma, respectively [16]. In our study, the recurrence rate in stage $\mathrm{Ib}$ gastric cancer patients with undifferentiated-type adenocarcinoma was higher than the rate in patients with differentiated-type, suggesting that the rate of relapse for patients with undifferentiated-type adenocarcinoma could be decreased by adjuvant oral chemotherapy.

In conclusion, the recurrence rate in stage $\mathrm{Ib}$ gastric cancer patients with undifferentiated-type adenocarcinoma was relatively high, and the prognosis of patients with recurrence was very poor. In those stage Ib gastric cancer patients with risk factors for recurrence, postoperative adjuvant chemotherapy may be a reasonable approach to improve the prognosis.

\section{References}

1. Ohtsu A, Yoshida S, Saijo N. Disparities in gastric cancer chemotherapy between the East and West. J Clin Oncol. 2006;24: 2188-96.

2. Japanese Gastric Cancer Association. Japanese classification of gastric carcinoma. 2nd English edition. Gastric Cancer 1998;1: $10-24$.

3. Sakuramoto S, Sasako M, Yamaguchi T, Kinoshita T, Fujii M, Nashimoto A, et al. Adjuvant chemotherapy for gastric cancer with S-1, an oral fluoropyrimidine. N Engl J Med. 2007;357: 1810-20.

4. Yoo CH, Noh SH, Shin DW, Choi SH, Min JS. Recurrence following curative resection for gastric carcinoma. Br J Surg. 2000; $87: 236-42$.

5. Sakar B, Karagol H, Gumus M, Basaran M, Kaytan E, Argon A, et al. Timing of death from tumor recurrence after curative gastrectomy for gastric cancer. Am J Clin Oncol. 2004;27:205-9.

6. Siewert JR, Bottcher K, Stein HJ, Roder JD. Relevant prognostic factors in gastric cancer: ten-year results of the German Gastric Cancer Study. Ann Surg. 1998;228:449-61.

7. Kim JW, Hwang I, Kim MJ, Jang SJ. Clinicopathological characteristics and predictive markers of early gastric cancer with recurrence. J Korean Med Sci. 2009;24:1158-64.

8. Folli S, Dente M, Dell'Amore D, Gaudio M, Nanni O, Saragoni L, et al. Early gastric cancer; prognostic factors in 223 patients. Br J Surg. 1995;82:952-6.

9. Ichiyoshi Y, Toda T, Minamisono Y, Nagasaki S, Yakeishi Y, Sugimachi K. Recurrence in early gastric cancer. Surgery. 1990; 107:489-95.

10. Lawrence M, Shiu MH. Early gastric cancer. Twenty-eight-year experience. Ann Surg. 1991;213:327-34.

11. Lee HJ, Kim YH, Lee KU, Lee KU, Choe KJ, Kim JP, et al. Clinicopathological analysis for recurrence of early gastric cancer. Jpn J Clin Oncol. 2003;33:209-14.

12. Takeuchi H, Kakeji Y, Tokunaga E, Koga T, Maehara Y, Sugimachi K. Prediction of recurrence after curative resection of gastric carcinoma invading the muscularis propria: a multivariate analysis. Gastric Cancer. 2000;3:28-32. 
13. Moriguchi S, Maehara Y, Korenaga D, Sugimachi K, Nose Y. Risk factors which predict pattern of recurrence after curative surgery for patients with advanced gastric cancer. Surg Oncol. 1992;1:341-6.

14. Fink AS, Longmire WP. Carcinoma of stomach. In: Subiston DC, editor. Textbook of surgery. 14th ed. Philadelphia: WB Saunders; 1991. p. 814-27.

15. Marutsuka T, Shimada S, Shiomori K, Hayashi N, Yagi Y, Yamane $\mathrm{T}$, et al. Mechanisms of peritoneal metastasis after operation for non- serosa-invasive gastric carcinoma: an ultrarapid detection system for intraperitoneal free cancer cells and a prophylactic strategy for peritoneal metastasis. Clin Cancer Res. 2003;9:678-85.

16. Koizumi W, Kurihara M, Nakano S, Hasegawa K. Phase II study of S-1, a novel oral derivative of 5-fluorouracil, in advanced gastric cancer. For the S-1 Cooperative Gastric Cancer Study Group. Oncology. 2000;58:191-7. 